\title{
Distribution of Acute and Chronic Lesions in the Sacroiliac Joints of Patients with Axial Spondyloarthritis
}

\author{
Churong Lin',* \\ Dong Liu ${ }^{2, *}$ \\ Budian Liu (iD) ${ }^{2}$ \\ Jieruo $\mathrm{Gu}^{2}$
}

'Department of Radiology, The Third Affiliated Hospital of Sun Yat-sen University, Guangzhou, People's Republic of China; ${ }^{2}$ Department of Rheumatology and Immunology, Third Affiliated Hospital of Sun Yat-sen University, Guangzhou, People's Republic of China

*These authors contributed equally to this work
Correspondence: Jieruo Gu Department of Rheumatology and Immunology, Third Affiliated Hospital of Sun Yat-sen University, No. 600 Tianhe Road, Tianhe District, Guangzhou, People's Republic of China Email gujieruo@I63.com
Objective: In this study, we aimed to investigate whether there was a pattern of distribution of acute and chronic lesions in the sacroiliac joints (SIJ) of patients with axial spondyloarthritis (axSpA).

Methods: A total of 96 patients diagnosed as axSpA were retrospectively included in this study. The Spondyloarthritis Research Consortium of Canada sacroiliac joint inflammation score (SIS) and structural score (SSS) were used to evaluate the acute and chronic lesions in the SIJs. Scores representing the distribution of bone marrow edema, fatty lesions and erosions were extracted respectively. By dividing the SIJs into sacral or iliac sections, upper or lower sections, anterior and posterior levels, differences of scores representing acute and chronic lesions were analyzed by Kruskal Wallis' tests.

Results: SIS scores were not significantly different in sacral or iliac sections, in upper or lower sections, on anterior or posterior levels. SSS scores were also not significantly different in different sections, except for higher occurrence rates of erosions in the iliac sections. Posthoc analysis showed that there was a higher erosion score in the left ilium than left sacrum, as well as in right ilium than left sacrum.

Conclusion: There was no specific distribution pattern of acute or chronic lesions in the SIJs in patients with axSpA. A bigger study sample was needed to confirm the distribution of erosions in sacral or iliac sections.

Keywords: magnetic resonance imaging, axial spondyloarthritis, ankylosing spondylitis, sacroiliac joint

\section{Introduction}

Axial spondyloarthritis (axSpA) is a spectrum of spondyloarthropathies featuring inflammation in the axial skeleton, including ankylosing spondylitis, psoriatic arthritis, reactive arthritis and undifferentiated spondyloarthritis. ${ }^{1,2}$ It often occurs to male patients, most commonly in the 20 s or $30 \mathrm{~s}$, with lower back pain as the typical initial symptoms. ${ }^{3,4}$ Delayed diagnosis often leads to long-lasting inflammation in the axial skeleton, which usually gives rise to structural damage, such as fatty lesions, erosions and ankylosis. ${ }^{5}$ Physical disability might be the consequences of such structural damage, greatly impairing patients' abilities of daily activities. ${ }^{6}$

The entire axial skeleton from cervical vertebrae to sacroiliac joints (SIJs) could be involved in axial spondyloarthritis. However, numerous studies have reported that the SIJs are usually the first spots to exhibit inflammation, known as bone marrow edema on the SIJ MRI. ${ }^{7,8}$ Other than bone marrow edema (BME), fatty 
lesions and erosions have also been widely studied, listed as the chronic lesions in the SIJs by the ASAS MRI working group. ${ }^{9}$ The Spondyloarthritis Research Consortium of Canada sacroiliac joint inflammation (SIS) and structural (SSS) scores are the two most common tools to assess inflammation and structural damage in the SIJs. ${ }^{10,11}$ They can reliably reflect the extent and severity of the inflammation and structural damage in the SIJs, therefore widely employed in clinical trials to monitor therapeutic responses. ${ }^{12}$

The imaging characteristics on SIJ MRI in patients with $\operatorname{axSpA}$ as well as the respective diagnostic values of different lesions have previously been discussed. A study by Seven et al investigated the morphological characteristics of SIJ MRI lesions in axial spondyloarthritis and control subjects, arriving at the conclusion that fatty lesions over $5 \mathrm{~mm}$ but not bone marrow edema over $10 \mathrm{~mm}$ could well differentiate axSpA patients from the control groups. ${ }^{13}$ Another study by Baraliakos et al concluded that structural lesions in SIJ, alone or in combination with BME, had high diagnostic values in patients suspected with axSpA. ${ }^{14}$ It has been debated whether structural damage in SIJ should be included in the definition of a positive SIJ MRI, yet the current definition of a positive SIJ MRI only consists of BME or osteitis. ${ }^{15}$

However, to the best of our knowledge, no study has ever investigated whether there is a difference in the distribution of acute and chronic lesions in the SIJs. This study intended to clarify the distribution of acute and chronic lesions in the SIJs in patients with axSpA. We hypothesized that the iliac side of the SIJs might be more susceptible to inflammation and structural damage since the iliac side needed to carry the weight of the axial skeleton.

\section{Methods}

\section{Patients}

Patients were retrospectively included in this study at the Third Affiliated Hospital of Sun Yat-sen University. Inclusion criteria were rheumatologists' clinical diagnosis of conditions pertaining to axial spondyloarthritis based on The International Classification of Diseases, Ninth Revision, Clinical Modification (ICD-9-CM) codes retrieved from the medical records. The included patients were further classified according to the 2009 ASAS classification criteria for axial spondyloarthritis. ${ }^{16}$ Clinical data such as age, sex, disease duration and HLA-B27 were retrieved from the medical records of the patients. This study was approved by the Ethical committee of the Third Affiliated Hospital of Sun Yat-sen University. Informed consent was waived by the ethical committee of the Third Affiliated Hospital of Sun Yatsen University upon the following considerations: 1) This study involves no more than minimal risks for the patients; 2) The study subjects had already left the hospital. All patient data were held in confidence and no individually identifiable patient information were included in this article. This study was conducted in compliance with the Declaration of Helsinki.

\section{MRI Scanning}

MRI images were retrieved from the PACS system. The MRI images were acquired on either a $1.5 \mathrm{~T}$ Optima MR360 (GE) or a 3.0 T Signa Architect (GE). T1weighted and $\mathrm{T} 2$ fat-saturated (T2-FS) sequences in a semi-coronal orientation and T2-FS sequences in a semiaxial orientation were obtained. Scoring of inflammation was based on T2-FS, while scoring of fat deposition and erosions was done based on T1-weighted images.

\section{Scoring of SIS and SSS}

A reader (CL) visually assessed the $\mathrm{T} 1 \mathrm{~W}$ and T2-FS images of all the included patients. The reader scrolled through all slices in a sagittal viewing direction. From all the slices, the reader evaluated the extent and severity of inflammation according to the Spondyloarthritis Research Consortium of Canada sacroiliac joint inflammation (SIS) and structural (SSS) scoring method. ${ }^{10,11}$

\section{Statistical Analysis}

All statistical analysis was performed in software packages $\mathrm{R}$ version 3.3 (The R Project for Statistical Computing, Vienna, Austria). Characteristics of study subjects were summarized using descriptive statistics. Shapiro's test was employed to examine the distribution of the characteristics. The mean $\pm \mathrm{SD}$ or the median and IQR were presented according to the distribution of the individual characteristics.

Within the SIS score of each individual, only the scores representing the distribution were extracted, while the scores representing the depth or intensity of inflammation were discarded. By dividing the SIJs into different sections, the sum of SIS scores and SSS scores were calculated, respectively, in each section. The sections included: 1) Right iliac, right sacral, left sacral and left iliac sections; 2) Upper section and lower section; 3) Levels 1-6 for SIS scores and levels 1-5 for SSS 
scores in the sagittal direction, representing anterior and posterior sections.

We used Kruskal Wallis' test to evaluate if there was a difference in the distribution of inflammation and structural lesions in different sections. If such differences were found, Dunn's test was used as the post-hoc test to analyse the pair-wise differences. Analysis of distribution of inflammatory and structural lesions were conducted in all patients, patients with r-axSpA and nr-axSpA, respectively. P-value $<0.05$ was considered statistically significant.

\section{Results}

\section{Patients}

A total of 96 patients diagnosed as axSpA were retrospectively included in this study. Of the 96 patients included, 67 were men and 29 were women. The mean (SD) age was 29.66 (8.11) years and the median (interquartile range) duration of disease was 3 [0.6275-7] years. Based on the 2009 ASAS classification criteria for axial spondyloarthritis, 45 were classified as nr-axSpA while 51 were classified as $\mathrm{r}$-axSpA based on radiographs according to the modified New York criteria. ${ }^{17}$

The median SIS scores for the nr-axSpA group and r-axSpA were 21.4 and 28.6, while the median SSS scores were 33.1 and 44.3. Twenty-three (24.0\%) of the 96 patients had been previously treated with bDMARDs. Three patients were treated with secukinumab, while 20 patients were treated with TNF- $\alpha$ inhibitors. Patient characteristics could be seen in Table 1 .

\section{Distribution of Inflammation in the SIJs}

The median and interquartile range of SIS scores in different sections are listed in Table 2. Kruskal-Wallis' tests showed that SIS scores were not significantly different in sacral or iliac sides, in upper or lower quadrants, on different levels in the sagittal direction.

\section{Distribution of Structural Lesions in the SIJs}

The median and interquartile range of SSS scores in different sections are listed in Table 2. Kruskal-Wallis' tests showed that SSS scores for erosions or fatty lesions were not significantly different on sacral or iliac sides, in upper or lower quadrants, on different levels in the sagittal direction. The only exception was erosions on the sacral or iliac sections. Post-hoc analysis of erosions in sacral of iliac sections could be seen in Table 3. Post-hoc analysis showed that there was a higher erosion score in the left ilium than left sacrum, as well as in right ilium than left sacrum. Ankylosis and backfills were not analyzed due to low occurrence rates.

By further classifying patients as nr-axSpA and $\mathrm{r}-\mathrm{axSpA}$, erosion scores were significantly higher on the iliac sides of the SIJs in patients with nr-axSpA, while the erosion scores were not significantly different on the iliac sides or sacral sides in patients with r-axSpA. Results of distribution of SIS scores and SSS scores in two groups of patients could be seen in Table 2 .

Jitters plots of the SIS scores and SSS scores could be seen in Figure 1.

\section{Discussion}

Other than genetic predisposition and gut microbiota, mechanical stress had been identified as another important risk factor in the etiology of axial spondyloarthritis. ${ }^{18}$ It had been observed that the spinal involvement of axSpA usually developed in an ascending fashion, with SIJs as the most involved axial joints and the earliest to manifest, while lesions in lumbar and thoracic vertebrae ensued. ${ }^{7,8}$ Numerous studies had linked the biomechanical stress to the development of axial

Table I Characteristics of Included Participants

\begin{tabular}{|l|l|l|l|}
\hline Characteristics & nr-axSpA (n=45) & r-axSpA (n=5I) & P-value \\
\hline Age (years), mean \pm SD & $28.3 \pm 7.84$ & $30.8 \pm 8.23$ & 0.134 \\
Male patients, $n$ (\%) & $27(60.00 \%)$ & $40(78.43 \%)$ & 0.082 \\
Disease duration (years), median [interquartile range] & $1[0.5-3]$ & $5[3-9.5]$ & $<0.00 I *$ \\
HLA-B27, $n$ (\%) & $34(75.56 \%)$ & $45(88.24 \%)$ & 0.175 \\
SIS, median [interquartile range] & $21.4[13-32]$ & $28.6[22.5-38.5]$ & $0.007^{*}$ \\
SSS, median [interquartile range] & $33.1[17-48]$ & $44.3[30-62]$ & $0.012^{*}$ \\
\hline
\end{tabular}

Note: $*_{p}<0.05$

Abbreviations: nr-axSpA, non-radiographic axial spondyloarthritis; r-axSpA, radiographic axial spondyloarthritis; SIS, sacroiliac joint inflammation score; SSS, structural score. 
Table 2 Distribution of Bone Marrow Edema (BME), Fatty Lesions and Erosions in the Sacroiliac Joints of Patients with axSpA

\begin{tabular}{|c|c|c|c|c|c|c|c|c|}
\hline \multirow[t]{2}{*}{ Patients } & \multirow[t]{2}{*}{ Sections } & & \multicolumn{2}{|l|}{ BME } & \multicolumn{2}{|c|}{ Fatty Lesions } & \multicolumn{2}{|l|}{ Erosions } \\
\hline & & & Score & $P$ value & Score & $P$ value & Score & $P$ value \\
\hline $\begin{array}{l}\text { All } \\
\text { patients }\end{array}$ & $\begin{array}{l}\text { Sacral or iliac sections } \\
\text { Upper or lower sections } \\
\text { Anterior or posterior } \\
\text { sections }\end{array}$ & $\begin{array}{l}\text { Right ilium } \\
\text { Right sacrum } \\
\text { Left sacrum } \\
\text { Left ilium } \\
\text { Upper } \\
\text { Lower } \\
\text { Level I } \\
\text { Level } 2 \\
\text { Level } 3 \\
\text { Level } 4 \\
\text { Level } 5 \\
\text { Level } 5\end{array}$ & $\begin{array}{l}3[0-10] \\
2[0-5] \\
2[0-6] \\
2[0-7] \\
6[0-12] \\
7.5[1-13.2] \\
2[0-5] \\
3[0-4] \\
2[0-4.25] \\
2[0-4] \\
1.5[0-4] \\
2[0-4]\end{array}$ & 0.3259 & $\begin{array}{l}\text { I [0-6] } \\
3[0-7] \\
3[0-5] \\
3[0-6] \\
3[0-12] \\
6[0-15] \\
2[0-4] \\
2[0-5] \\
2[0-5] \\
2[0-6] \\
2[0-5] \\
-\end{array}$ & $\begin{array}{l}0.2556 \\
0.6558\end{array}$ & $\begin{array}{l}8[5-10] \\
6[2-9] \\
8[5-10] \\
7[2-10] \\
14[8-19] \\
13.5[7.75- \\
19] \\
6[1-8] \\
6[2.75-8] \\
6[3.75-8] \\
6[3.75-8] \\
6[3-8] \\
-\end{array}$ & $0.01367 *$ \\
\hline$r$-axSpA & $\begin{array}{l}\text { Sacral or iliac sections } \\
\text { Upper or lower sections } \\
\text { Anterior or posterior } \\
\text { sections }\end{array}$ & $\begin{array}{l}\text { Right ilium } \\
\text { Right sacrum } \\
\text { Left sacrum } \\
\text { Left ilium } \\
\text { Upper } \\
\text { Lower } \\
\text { Level I } \\
\text { Level } 2 \\
\text { Level } 3 \\
\text { Level } 4 \\
\text { Level } 5 \\
\text { Level } 6\end{array}$ & $\begin{array}{l}4[0-9] \\
3[0-7.5] \\
2[0-6] \\
6[0-11.5] \\
9[2.5-13.5] \\
9[2-16.5] \\
4[1-5.5] \\
4[1-6] \\
4[0.5-5] \\
3[0.5-5] \\
2[0.5-4.5] \\
2[0-4.5]\end{array}$ & $\begin{array}{l}0.2483 \\
0.7548 \\
0.644\end{array}$ & $\begin{array}{l}5[0.5-8.5] \\
5[1-9] \\
5[0-9] \\
5[0-9] \\
7[2-15] \\
10[4.5-18] \\
2[0-6] \\
4[1-7] \\
5[2-6.5] \\
5[1-7.5] \\
4[1.5-7.5] \\
-\end{array}$ & $\begin{array}{l}0.1157 \\
0.6398\end{array}$ & $\begin{array}{l}10[7.5-10] \\
10[7-10] \\
9[5.5-10] \\
10[8-10] \\
18[14-20] \\
18[12.5-20] \\
8[5.5-8] \\
8[4-8] \\
8[5.5-8] \\
8[5.5-8] \\
8[6-8] \\
-\end{array}$ & $\begin{array}{l}0.705 \\
0.9089\end{array}$ \\
\hline$n r-a x S p A$ & $\begin{array}{l}\text { Sacral or iliac sections } \\
\text { Upper or lower sections } \\
\text { Anterior or posterior } \\
\text { sections }\end{array}$ & $\begin{array}{l}\text { Right ilium } \\
\text { Right sacrum } \\
\text { Left sacrum } \\
\text { Left ilium } \\
\text { Upper } \\
\text { Lower } \\
\text { Level I } \\
\text { Level } 2 \\
\text { Level } 3 \\
\text { Level } 4 \\
\text { Level } 5 \\
\text { Level } 6\end{array}$ & $\begin{array}{l}\text { I }[0-5] \\
0[0-4] \\
\text { I }[0-4] \\
2[0-6] \\
2[0-7] \\
5[0-1 \mathrm{II}] \\
\text { I }[0-4] \\
2[0-4] \\
\text { I }[0-3] \\
0[0-3] \\
\text { I }[0-3] \\
0[0-3]\end{array}$ & $\begin{array}{l}0.2188 \\
0.7187\end{array}$ & $\begin{array}{l}\text { I [0-3] } \\
0[0-3] \\
0[0-3] \\
0[0-2] \\
\text { I [0-5] } \\
\text { I [0-6] } \\
0[0-2] \\
0[0-2] \\
\text { I }[0-2] \\
\text { I }[0-3] \\
0[0-2] \\
-\end{array}$ & $\begin{array}{l}0.8172 \\
0.8679\end{array}$ & $\begin{array}{l}6[3-8] \\
3[0-6] \\
3[0-6] \\
6[2-8] \\
9[3-13] \\
9[5-14] \\
3[0-6] \\
4[1-6] \\
4[2-6] \\
4[2-5] \\
3[1-5] \\
-\end{array}$ & $\begin{array}{l}0.7431 \\
0.5899\end{array}$ \\
\hline
\end{tabular}

Note: $* \mathrm{P}<0.05$.

Abbreviations: BME, bone marrow edema; r-axSpA, radiographic axial spondyloarthritis; nr-axSpA, non-radiographic axial spondyloarthritis.

spondyloarthritis. A patient-reported survey revealed that a large proportion of patients with ankylosing spondylitis reported physical trauma, exercise and physiotherapy as potential triggers for AS symptoms. ${ }^{19}$ A study of the joint anatomy of SIJs suggested that proportions of atypical joints were significantly higher in axSpA patients than in controls, possibly due to the supra-physiological biomechanical stress exerted by atypical joint forms. ${ }^{20}$ Moreover, the mechanosensitive Wnt/beta-Catenin signaling pathway might potentially explain the ectopic bone formation in the axial skeleton in axSpA. ${ }^{21-23}$ Therefore, it was natural to assume that acute and chronic lesions might be distributed differently in the sacroiliac joints in patients with axSpA. We hypothesized that these lesions might be more prevalent on the iliac side since the ilium had to carry the weight of the entire axial skeleton. 
Table 3 Post-hoc Analysis of Erosions in the Sacral or Iliac Sections in Patients with axSpA

\begin{tabular}{|l|l|l|}
\hline Comparison & Z Value & P value \\
\hline Left ilium - Left sacrum & 2.62030925 & $0.04392503^{*}$ \\
Left ilium - Right ilium & -0.0450635 & 0.9640567 \\
Left sacrum - Right ilium & -2.6653727 & $0.04614182^{*}$ \\
Left ilium - Right sacrum & 1.80784108 & 0.21189371 \\
Left sacrum - Right sacrum & -0.8124682 & 0.83304609 \\
Right ilium - Right sacrum & 1.85290457 & 0.25558415 \\
\hline
\end{tabular}

Note: ${ }^{*} p<0.05$

However, results showed that there were no differences in the distribution of the inflammatory lesions as well as structural lesions in the SIJs. The only odd exception was erosions on the sacral or iliac sides. Post-hoc analysis showed that there was a higher erosion score in the left ilium than left sacrum, as well as in right ilium than left sacrum. We believed this result was not necessarily meaningful, since the sample size was not large enough. However, if this result could be replicated in a study with a larger study sample, it could be indicated that structural lesions, especially erosions, were more likely to develop on the iliac sides of the SIJ. This could serve as circumstantial evidence that biomechanical stress could induce the development of structural damage of the SIJ in patients with axSpA. Overall, by dividing the SIJs into different sections, the distributions of such lesions were comparable on the sacral or iliac sides, in the upper or lower quadrants, or on different levels in the sagittal direction. This could be explained by the anatomy of the SIJs. SIJs connect the spine to the pelvis, thus transferring the load from the lumbar spine to the lower extremities. ${ }^{24}$ Noteworthy, SIJs were rather stable, allowing minimal motion in this joint. Such stability could be attributed to the support of muscles and ligaments. ${ }^{24}$ The highly stable structure of the SIJs could potentially prevent the accumulation of mechanical stress exerted on certain quadrants of the SIJs.

Interestingly, the distribution of lesions in the spine might be a different case. A CT study of the spine in patients with ankylosing spondylitis revealed that syndesmophytes were not randomly distributed along the vertebral rim. ${ }^{25}$ Syndesmophytes preferentially occurred at the posterolateral rim of the vertebrae, while least common at the posterior rim and anterior rim. One possible explanation was that the biomechanical properties of the middle column differed from the anterior or posterior elements. ${ }^{26}$ Yet, it had not been investigated whether there was a pattern of lesion distribution in the SIJs in patients with axSpA. Our study was the first one to show that bone marrow edema and fat deposition were evenly distributed in the SIJs, while erosions were more likely to develop on the iliac sides. Further analysis showed that this discrepancy mainly occurred in patients in nr-axSpA, while in patients with r-axSpA erosions were evenly distributed. It was possible that long-standing inflammation of the SIJs could eventually lead to structural damage on both sides of the SIJs.

Although results failed to prove our hypothesis, we believed our study still bore clinical significance. It could be employed to examine the validity of a batch of MR images. If a certain batch of MR images consistently showed elevated signals on one side, it was justified to have scruples about whether the imaging modalities or imaging parameters were faulty. Measures should be taken to adjust the scanner or the imaging parameters so as to ensure the credibility of the images. Secondly, it could serve as circumstantial evidence to support the hypothesis that biomechanical stress was an important etiological factor in the disease mechanism of axSpA.

There were several limitations to this study. First, disease activity parameters such as BASDAI or ASDAS were not retrieved since related information was not properly recorded in the medical records. Therefore, the overall disease activity status of the included patients could not be estimated. Second, this study did not stratify included patients according to age, sex, disease activity or disease duration. We could not rule out the possibility that there was a certain distribution pattern of lesions in a specific subset of patients. Third, the study sample was relatively small. The actual distribution pattern might be revealed under a bigger study sample. Fourth, given the fact that this was a cross-sectional study, we did not investigate the effect of therapy, especially bDMARDs, on the distribution of lesions in the SIJs. 
A



D

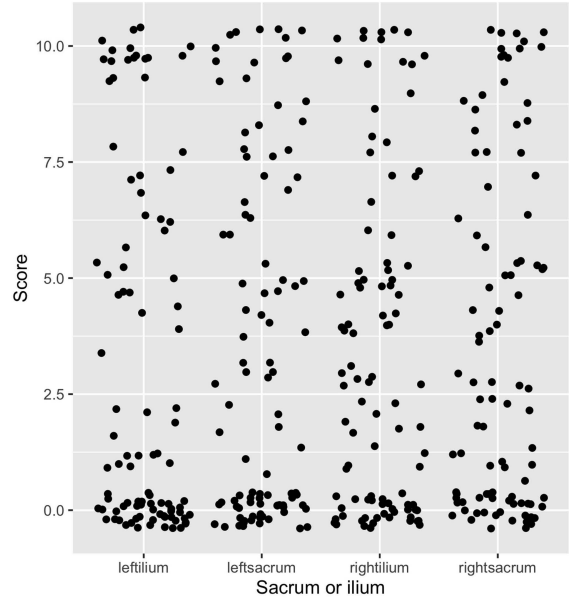

G

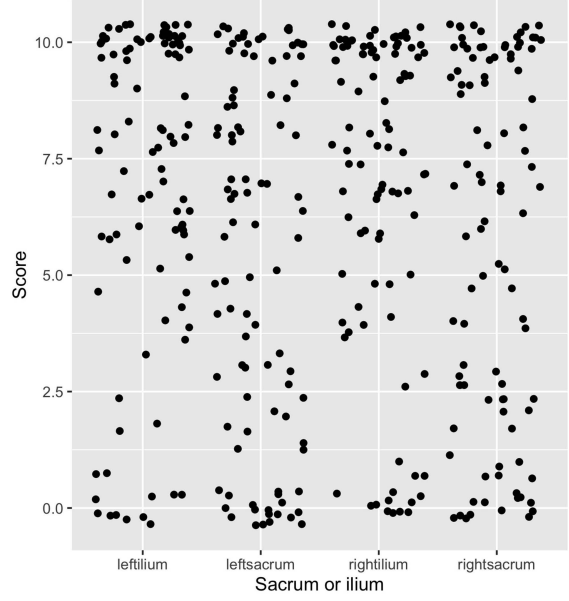

B



E



H

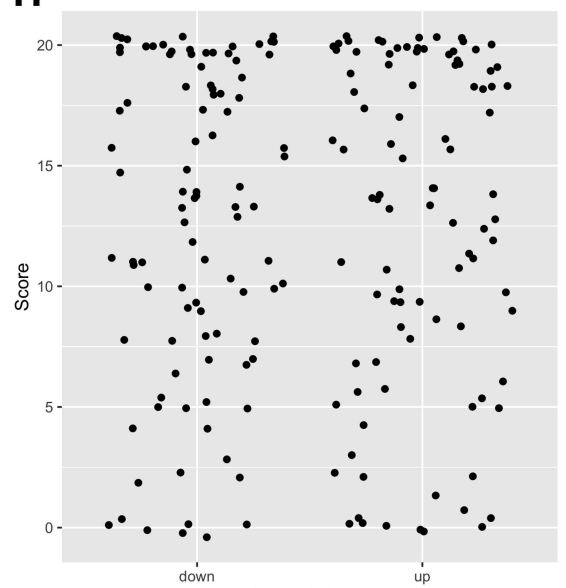

C

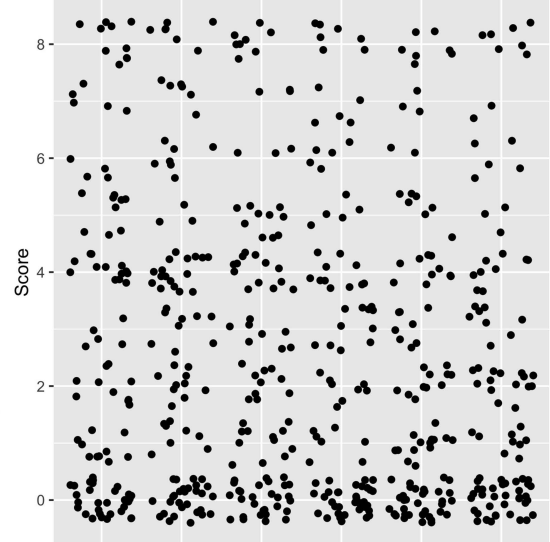

$\mathbf{F}$

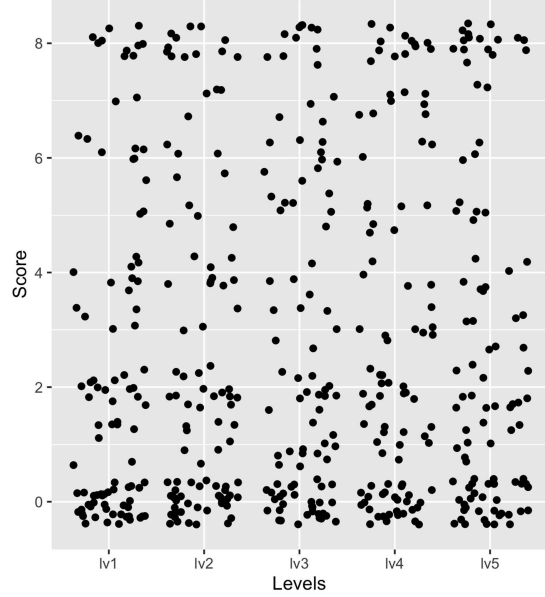

I



Figure I jitter plots of bone marrow edema (BME), fatty lesions and erosions in the sacroiliac joints of patients with axial spondyloarthritis. (A) BME in sacral or iliac sections; (B) BME in upper or lower sections; (C) BME in anterior or posterior sections; (D) fatty lesions in sacral or iliac sections; (E) fatty lesions in upper or lower sections; (F) fatty lesions in anterior or posterior sections; (G) erosions in sacral or iliac sections; (H) erosions in upper or lower sections; (I) erosions in anterior or posterior sections.

In conclusion, the acute and chronic lesions in the SIJs in patients with axSpA were evenly distributed, except that erosions were more likely to develop on the iliac sides of the SIJs. This result could be applied to examine whether the imaging modalities or the imaging parameters were faulty if a batch of images consistently showed higher 
signal on one side. It could also serve as circumstantial evidence that biomechanical stress was involved in the etiology of axSpA.

\section{Disclosure}

The authors report no conflicts of interest in this work.

\section{References}

1. Rudwaleit M, Haibel H, Baraliakos X, et al. The early disease stage in axial spondylarthritis: results from the German spondyloarthritis inception cohort. Arthritis Rheum. 2009;60(3):717-727. doi:10.1002/ art.24483

2. Robinson PC, van der Linden S, Khan MA, Taylor WJ. Axial spondyloarthritis: concept, construct, classification and implications for therapy. Nat Rev Rheumatol. 2021;17(2):109-118. doi:10.1038/ s41584-020-00552-4

3. Sieper J, Braun J, Dougados M, Baeten D. Axial spondyloarthritis. Nat Rev Dis Primers. 2015;1(1):15013. doi:10.1038/nrdp.2015.13

4. Dean LE, Jones GT, MacDonald AG, Downham C, Sturrock RD, Macfarlane GJ. Global prevalence of ankylosing spondylitis. Rheumatology. 2014;53(4):650-657. doi:10.1093/rheumatology/ket387

5. Sepriano A, Ramiro S, Landewe R, Dougados M, van der Heijde D, Rudwaleit M. Is active sacroiliitis on MRI associated with radiographic damage in axial spondyloarthritis? Real-life data from the ASAS and DESIR cohorts. Rheumatology. 2019;58(5):798-802. doi:10.1093/rheumatology/key387

6. Protopopov M, Sieper J, Haibel H, Listing J, Rudwaleit M, Poddubnyy D. Relevance of structural damage in the sacroiliac joints for the functional status and spinal mobility in patients with axial spondyloarthritis: results from the German spondyloarthritis inception cohort. Arthritis Res Ther. 2017;19(1):240. doi:10.1186/s13075-017-1453-3

7. Herrada I, Devilliers H, Fayolle C, et al. Diagnostic performance of sacroiliac and spinal MRI for the diagnosis of non-radiographic axial spondyloarthritis in patients with inflammatory back pain. Joint Bone Spine. 2021;88(2):105106. doi:10.1016/j.jbspin.2020.105106

8. Braun J, Kiltz U, Baraliakos X. Significance of structural changes in the sacroiliac joints of patients with axial spondyloarthritis detected by MRI related to patients symptoms and functioning. Ann Rheum Dis. 2021. doi:10.1136/annrheumdis-2021-221406

9. Maksymowych WP, Lambert RG, Ostergaard M, et al. MRI lesions in the sacroiliac joints of patients with spondyloarthritis: an update of definitions and validation by the ASAS MRI working group. Ann Rheum Dis. 2019;78(11):1550-1558. doi:10.1136/annrheumdis-2019215589

10. Maksymowych WP, Inman RD, Salonen D, et al. Spondyloarthritis research consortium of Canada magnetic resonance imaging index for assessment of sacroiliac joint inflammation in ankylosing spondylitis. Arthritis Rheum. 2005;53(5):703-709. doi:10.1002/art.21445

11. Maksymowych WP, Wichuk S, Chiowchanwisawakit P, Lambert RG, Pedersen SJ. Development and preliminary validation of the spondyloarthritis research consortium of Canada magnetic resonance imaging sacroiliac joint structural score. $J$ Rheumatol. 2015;42(1):79-86. doi:10.3899/jrheum. 140519

12. van der Heijde D, Baraliakos X, Hermann KA, et al. Limited radiographic progression and sustained reductions in MRI inflammation in patients with axial spondyloarthritis: 4-year imaging outcomes from the RAPID-axSpA Phase III randomised trial. Ann Rheum Dis. 2018;77(5):699-705. doi:10.1136/annrheumdis-2017-212377
13. Seven S, Ostergaard M, Morsel-Carlsen L, et al. Morphological characteristics of sacroiliac joint MRI lesions in axial spondyloarthritis and control subjects. Rheumatology. 2021. doi:10.1093/rheumatology/keab468

14. Baraliakos X, Ghadir A, Fruth M, Kiltz U, Redeker I, Braun J. Which magnetic resonance imaging lesions in the sacroiliac joints are most relevant for diagnosing axial spondyloarthritis? A Prospective study comparing rheumatologists' evaluations with radiologists' findings. Arthritis Rheumatol. 2021;73(5):800-805. doi:10.1002/art.41595

15. Lambert RG, Bakker PA, van der Heijde D, et al. Defining active sacroiliitis on MRI for classification of axial spondyloarthritis: update by the ASAS MRI working group. Ann Rheum Dis. 2016;75 (11):1958-1963. doi:10.1136/annrheumdis-2015-208642

16. Rudwaleit M, van der Heijde D, Landewe R, et al. The development of assessment of SpondyloArthritis international society classification criteria for axial spondyloarthritis (part II): validation and final selection. Ann Rheum Dis. 2009;68(6):777-783. doi:10.1136/ ard.2009.108233

17. Goie The HS, Steven MM, van der Linden SM, Cats A. Evaluation of diagnostic criteria for ankylosing spondylitis: a comparison of the Rome, New York and modified New York criteria in patients with a positive clinical history screening test for ankylosing spondylitis. $\mathrm{Br}$ J Rheumatol. 1985;24(3):242-249. doi:10.1093/rheumatology/24.3.242

18. Hwang MC, Ridley L, Reveille JD. Ankylosing spondylitis risk factors: a systematic literature review. Clin Rheumatol. 2021;40 (8):3079-3093. doi:10.1007/s10067-021-05679-7

19. Ansell RC, Shuto T, Busquets-Perez N, Hensor EM, Marzo-Ortega $\mathrm{H}$, McGonagle D. The role of biomechanical factors in ankylosing spondylitis: the patient's perspective. Reumatismo. 2015;67(3):91-96. doi:10.4081/reumatismo.2015.853

20. Ziegeler K, Kreutzinger V, Proft F, Poddubnyy D, Hermann KGA, Diekhoff T. Joint anatomy in axial spondyloarthritis: strong associations between sacroiliac joint form variation and symptomatic disease. Rheumatology. 2021. doi:10.1093/rheumatology/keab318

21. Tonuk SB, Yorgancioglu ZR. Biomechanical factors in psoriatic disease: defective repair exertion as a potential cause. hypothesis presentation and literature review. ACR Open Rheumatol. 2019;1 (7):452-461. doi:10.1002/acr2.11056

22. Li X, Wang J, Zhan Z, et al. Inflammation intensity-dependent expression of osteoinductive Wnt proteins is critical for ectopic new bone formation in ankylosing spondylitis. Arthritis Rheumatol. 2018;70(7):1056-1070. doi:10.1002/art.40468

23. Burgers TA, Williams BO. Regulation of Wnt/beta-catenin signaling within and from osteocytes. Bone. 2013;54(2):244-249. doi:10.1016/ j.bone.2013.02.022

24. Kiapour A, Joukar A, Elgafy H, Erbulut DU, Agarwal AK, Goel VK. Biomechanics of the sacroiliac joint: anatomy, function, biomechanics, sexual dimorphism, and causes of pain. Int J Spine Surg. 2020;14(Suppl 1):3-13. doi:10.14444/6077

25. Tan S, Dasgupta A, Yao J, Flynn JA, Yao L, Ward MM. Spatial distribution of syndesmophytes along the vertebral rim in ankylosing spondylitis: preferential involvement of the posterolateral rim. Ann Rheum Dis. 2016;75(11):1951-1957. doi:10.1136/annrheumdis-2015-208802

26. Su Q, Li C, Li Y, et al. Analysis and improvement of the three-column spinal theory. BMC Musculoskelet Disord. 2020;21 (1):537. doi:10.1186/s12891-020-03550-5 


\section{Publish your work in this journal}

The International Journal of General Medicine is an international, peer-reviewed open-access journal that focuses on general and internal medicine, pathogenesis, epidemiology, diagnosis, monitoring and treatment protocols. The journal is characterized by the rapid reporting of reviews, original research and clinical studies across all disease areas. The manuscript management system is completely online and includes a very quick and fair peer-review system, which is all easy to use. Visit http://www.dovepress.com/ testimonials.php to read real quotes from published authors. 